\title{
Die Löslichkeit von Alkalimetallsalzen in den dazu gehörigen Säuren.
}

\author{
Von \\ W. HERZ.
}

Bei der Durchsicht der Literatur fiel mir auf, dafs für die Löslichkeiten der Alkalimetallsalze in den zugehörigen Säuren keine genauen Zahlen angegeben werden; ich habe infolgedessen einige quantitative Versuche darüber angestellt. Die Löslichkeitsangaben beziehen sich auf $25^{\circ}$.

Die Löslichkeitsbestimmungen von Alkalichloriden in Salzsäure erfolgten derart, dafs das Salz im Überschufs mit den Chlorwasserstofflösungen bis zur völligen Sättigung geschüttelt wurde. Von der klaren Lösung pipettierte ich eiı bestimmtes Quantum ab, in dem zuerst der Säuregehalt durch Kalilauge mit Phenolphtalein als Indikator zur Bestimmung gelangte; darauf wurde die Lösung zur Entfernung der Rotfärbung mit einem Tropfen Essigsäure versetzt, einige Tropfen Kaliumchromatlösung hinzugegeben und der Chlorionengehalt mit Silberiösung titriert; durch Subtraktion der den Wasserstoffionen entsprechenden Quantität Halogenionen von der Gesamtmenge erhält man den Gehalt an gelöstem Salz.

Die folgenden Löslichkeitsangaben bedeuten Millimole in $10 \mathrm{ccm}$ Lösung.

Löslichkeî von $\mathrm{LiCl} \cdot \mathrm{H}_{2} \mathrm{O}$ in Salzsäurelösungen.

$\begin{array}{rr}\mathrm{HCl} & \mathrm{LiCl} \\ - & 135.36 \\ 6.30 & 134.14 \\ 10.53 & 126.52 \\ 17.64 & 122.58\end{array}$

Löslichkeit von $\mathrm{NaCl}$ in Salzsäurelösungen.

$\begin{array}{rr}\mathrm{HCl} & \mathrm{NaCl} \\ - & 54.56 \\ 6.07 & 48.50 \\ 10.32 & 44.67 \\ 15.90 & 37.82 \\ 21.17 & 32.97 \\ 32.83 & 23.43\end{array}$


Die Töslichkeit von Allalimetallsalzen in den dazu gehörigen Säntren. 275

Löslichkeit von $\mathrm{KCl}$ in Salzsäurelösungen.

$\mathrm{HCl}$

5.66

10.20

15.90

20.94

32.52
$\mathrm{KCl}$

42.72

37.49

33.79

28.68

24.74

17.39

Trägt man in ein Koordinatensystem auf der Abszissenachse die Salzmengen und auf der Ordinatenachse die dazu gehörigen Säurequantitüten ein, so liefern die Löslichkeitserniedrigungen gerade Linien.

Löslichkeit von $\mathrm{KCl}$ in Bromwasserstoffsäurelösungen.

Die Bestimmungsmethode war die gleiche wie vorher. - Da hier eine - wegen der starken Dissoziation allerdings nur geringfügige - Umsetzung verlaufen mufs, so ist zu erwarten, dals der Löslichkeitsrückgang etwas kleiner als in Salzsäure ausfällt. was auch tatsächlich der Fall ist.

$\begin{array}{rr}\mathrm{H} \cdot & \text { Salz } \\ - & 42.72 \\ 6.61 & 37.80 \\ 34.15 & 19.57\end{array}$

Löslichkeit von $\mathrm{NaC}_{2} \mathrm{H}_{3} \mathrm{O}_{2}, 3 \mathrm{H}_{2} \mathrm{O}$ in Essigsäurelösung.

Infolge der geringen Dissoziation der Essigsäure ist vorauszusehen, dals die Löslichkeitszurückdrängung des Natriumacetats nicht sehr erheblich sein wird. Andererseits wird die Fähigkeit des Natriumacetats zur Bildung saurer Salze eine Löslichkeitserhöhung ergeben. Die beobachtete Löslichkeitsbeeinflussung wird sich aus diesen beiden Wirkungen zusammensetzen, und das Resultat ist, wic die folgenden Zahlen zeigen, dar's nur eine ganz geringe Löslichkeitsabnahme stattfindet.

Die Bestimmung erfolgte derart, dafs Salz im Überschufs mit dem Lösungsmittel bis zur Einstellung des Gleichgewichtes geschüttelt wurde. In einem Teile der klaren abpipettierten Lösung wurde der Säuregehalt titrimetrisch festgestellt; ein anderer Teil wurde in einem Platintiegel mit Schwefelsäure eingedampft, die überschüssige Schwefelsäure abgeraucht und der Tiegel nach Zusatz von etwas Ammoniumkarbonat bis zur Gewichtskonstanz geglüht. 
Aus dem so erhaltenen Natriumsulfat folgt die gelöste Natriumacetatmenge.

$$
\begin{array}{cc}
\mathrm{HC}_{2} \mathrm{H}_{8} \mathrm{O} & \mathrm{NaC}_{2} \mathrm{H}_{3} \mathrm{O} \\
- & 47.75 \\
24.16 & 47.30
\end{array}
$$

Bei der Auflösung von Alkalisulfaten in Schwefelsäurelösungen übertrifft der Einflufs der Fähigkeit zur Bildung saurer Salze derart die Löslichkeitsverminderung durch das gleichionige Lösungsmittel, dafs keine Löslichkeitserniedrigung sondern eine -erhöhung herauskommt.

Die Salze wurden im Überschufs mit Schwefelsäurelösungen geschüttelt. In einem abpipettierten Quantum der klaren Gleichgewichtslösung wurde der. Säuregehalt titrimetrisch und nach dem Ansäuern mit Salzsüure der gesamte Sulfatgehalt mittels Fällung mit Bariumchlorid gewichtsanalytisch bestimmt. Durch Abzug der den Wasserstoffionen entsprechenden Quantität Bariumsulfat von der Gesamtmenge folgt der Salzgehalt.

Löslichkeit ron $\mathrm{Na}_{2} \mathrm{SO}_{4} \cdot 10 \mathrm{H}_{2} \mathrm{O}$ in Schwefelsäurelösungen.

$\begin{array}{cc}\mathrm{H}_{2} \mathrm{SO}_{4} & \mathrm{Na}_{2} \mathrm{SO}_{4} \\ - & 18.81 \\ 5.10 & 22.38 \\ 7.79 & 24.65\end{array}$

Löslichkeit von $\mathrm{K}_{2} \mathrm{SO}_{4}$ in Schwefelsäurelösungen.

$\begin{array}{rr}\mathrm{H}_{2} \mathrm{SO}_{4} & \mathrm{~K}_{2} \mathrm{SO}_{4} \\ - & 6.17 \\ 3.97 & 8.92 \\ 7.57 & 10.82 \\ 14.35 & 14.86\end{array}$

Die Löslichkeitserhöhungen liefern gerade Linien, wenn man in ein Koordinatensystem auf der Abszissenachse die Salzmengen und auf der Ordinatenachse die entsprechenden Säurequantitäten einträgt.

Herrn cand. W. Rathmann, der mich bei der Ausführung der Analysen aufs beste unterstützte, sage ich für seine Hilfe besten Dank.

Breslau, Pharmaxeutisches Institut der Universität, 31. Oktober 1911.

Bei der Redaktion eingegangen am 1. Nóvember 1911. 